\title{
Abnormal platelet aggregation in patients with Raynaud's phenomenon
}

\author{
M L BIONDI, B MARASINI \\ From the Clinica Medica V, Università degli Studi di Milano, Ospedale San Paolo, Milan, Italy
}

SUMMARY Platelet aggregation in vitro to several aggregating agents (serotonin (5-HT), adenosine diphosphate, adrenaline and collagen) was studied in 16 patients with primary and secondary Raynaud's phenomenon and compared with that in 13 normal volunteers. Platelets from patients with Raynaud's phenomenon had significantly greater responses to all the 5-HT concentrations tested ( $\mathrm{p}<0.001$ for $10 \mu \mathrm{M} ; \mathrm{p}<0.01$ for $1 \mu \mathrm{M}$; $\mathrm{p}<0.05$ for $0.1 \mu \mathrm{M} ; \mathrm{p}<0.02$ for $0.025 \mu \mathrm{M}$ ) and to low doses of adenosine diphosphate ( $<<0.01$ for $1 \mu \mathrm{M} ; \mathrm{p}<0.02$ for $0.5 \mu \mathrm{M}$ ) but normal responses to collagen, adrenaline, and high doses of adenosine diphosphate. Patients with secondary Raynaud's phenomenon were significantly more hypersensitive to $0.5 \mu \mathrm{M}$ adenosine diphospate than patients with primary Raynaud's phenomenon. In patients with secondary Raynaud's phenomenon there was a significant correlation between the extent of 5-HT aggregation and the duration of the disease.

The finding that platelets from patients with Raynaud's phenomenon have enhanced responses to 5-HT and adenosine diphosphate, but normal responses to adrenaline and collagen, is consistent with a role for 5-HT in this disease.

The role of serotonin $(5-\mathrm{HT})$ in the pathogenesis of Raynaud's phenomenon is still unclear. Even though abnormal intraplatelet and circulating 5-HT concentrations have been found in patients with the syndrome,' inconsistent results of clinical trials with ketanserin, a selective 5-HT2 receptor antagonist, ${ }^{2-6}$ make it difficult to establish whether 5-HT is of primary aetiological importance or merely represents an epiphenomenon, at least partially related to abnormally activated platelets in vivo. ${ }^{7-9}$.

We looked at the association between 5-HT and platelets in the pathogenesis of Raynaud's phenomenon, comparing the in vitro responses of platelets from patients with Raynaud's phenomenon with several aggregating substances, including 5-HT.

\section{Material and methods}

Sixteen patients (14 women and two men, mean (SE) age 46 (3) years, range 21 to 65 years) with Raynaud's phenomenon were studied. Nine had primary Raynaud's disease and seven had Raynaud's syndrome secondary to progressive systemic sclerosis. The diagnosis was based on accepted criteria. ${ }^{10}$ The mean (SE) duration of disease was 16 (3) years, range

Accepted for publication 16 February 1989 two to $\mathbf{4 0}$ years. None had evidence of cardiovascular disease or diabetes mellitus. Thirteen healthy volunteers, matched for age and sex, served as controls. None of the subjects, including controls, had taken any drug for at least two weeks before sampling.

Blood was collected without stasis, between 9 am and 11 am after an overnight fast and mixed with $1 / 10$ volume of $3.8 \%$ sodium citrate and centrifuged at $130 \times g$ for 15 minutes at room temperature (plateletrich plasma). Platelet-rich plasma was diluted with platelet-poor plasma, prepared by higher speed centrifugation $\left(950 \times g\right.$ for 20 minutes), to $3.0(0.5) \times 10^{5}$ platelets $/ \mu 1$. Platelet counts were made with a Thrombocounter C.

A Born-type aggregometer (Elvi 640) was used to test platelet aggregation. Aggregation was expressed as the maximum increase in optical density four minutes after the addition of the aggregating agents. The following concentrations were used: $5-\mathrm{HT}-10 ; 1$; $0 \cdot 1 ; 0.025 \mu \mathrm{M}$; collagen -4;1.6;0.8;0.4 $\mu \mathrm{g} / \mathrm{ml}$; adrenaline - $10 ; 2 ; 1 ; 0.5 \mu \mathrm{M}$, adenosine diphosphate (ADP) $4 ; 2 ; 1 ; 0 \cdot 5 \mu \mathrm{M}$.

Statistical analysis was performed using a MannWhitney $U$ test to compare unpaired data and by determining linear correlation coefficients. Data were expressed as median values plus the range of observations, unless otherwise specified. 
Results

A wide range of concentrations for each aggregating substance was used to ensure that platelet hypersensitivity, which is likely to be found with low concentrations of agents, did not go unnoticed.

Platelets from patients with Raynaud's phenomenon had significantly greater aggregation to all the concentrations of $5-\mathrm{HT}(10 ; 1 ; 0 \cdot 1 ; 0 \cdot 025 \mu \mathrm{M})$, but had significantly greater responses to ADP only when low doses $(1$ and $0.5 \mu \mathrm{M})$ were used. Normal responses were observed to collagen $(4 ; 1 \cdot 6 ; 0 \cdot 8 ; 0 \cdot 4 \mu \mathrm{g} / \mathrm{ml})$, adrenaline $(10 ; 2 ; 1 ; 0.5 \mu \mathrm{M})$, and to higher ADP concentrations ( 4 and $2 \mu \mathrm{M}$ ) (table 1$)$. The mean threshold concentrations of 5-HT and ADP needed to induce aggregation were significantly lower in patients than in controls (5-HT- $0.06(0.01) v 0.97(0.75) \mu \mathrm{M}, \mathrm{p}<$ 0.001; ADP-1.0 (0.2) v $1.7(0.1) \mu \mathrm{M}, \mathrm{p}<0.01$, patients $v$ controls). No differences were observed for threshold concentrations of collagen and adrenaline (collagen-1.0 (0.3) $v 1.2(0.3) \mu \mathrm{g} / \mathrm{ml}$; adrenaline-2.7 (1.0) $v 4.4(1.2) \mu \mathrm{M}$, patients $v$ controls).

Platelet response to agonists did not distinguish between primary and secondary Raynaud's phenomenon, with the exception of low dose ADP (table 2). Platelets from patients with Raynaud's phenomenon associated with progressive systemic sclerosis showed enhanced responses to $0.5 \mu \mathrm{M}$ ADP (7.3(0-17.6) $v$ $0(0-4.2) \mathrm{cm}, \mathrm{p}<0.02$, secondary $v$ primary Raynaud's phenomenon). Aggregation of platelets from patients with secondary Raynaud's phenomenon to low doses of 5-HT $(1$ and $0 \cdot 1 \mu \mathrm{M})$ were significantly correlated with the duration of disease (fig).

Table 1 Platelet responses to 5-HT, ADP, adrenaline and collagen in 16 patients with Raynaud's phenomenon and 13 healthy controls

\begin{tabular}{|c|c|c|c|c|c|}
\hline \multirow{2}{*}{$\frac{\text { Agonist }}{5-\mathrm{HT}}$} & \multirow{2}{*}{$\begin{array}{l}\text { Dose } \\
10.0 \mu \mathrm{M} \\
1.0 \mu \mathrm{M} \\
0.1 \mu \mathrm{M} \\
0.025 \mu \mathrm{M}\end{array}$} & \multicolumn{2}{|c|}{ Patients } & \multicolumn{2}{|c|}{ Controls } \\
\hline & & $\begin{array}{r}12 \cdot 3 \\
13 \cdot 4 \\
7 \cdot 7 \\
0.0\end{array}$ & 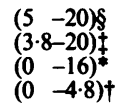 & $\begin{array}{l}6 \cdot 3 \\
5 \cdot 5 \\
0 \cdot 0 \\
0 \cdot 0\end{array}$ & $\begin{array}{l}(1 \cdot 7-8) \\
(0-12) \\
(0-10 \cdot 2)\end{array}$ \\
\hline ADP & $\begin{array}{l}4.0 \mu \mathrm{M} \\
2.0 \mu \mathrm{M} \\
1.0 \mu \mathrm{M} \\
0.5 \mu \mathrm{M}\end{array}$ & $\begin{array}{r}13.6 \\
12.6 \\
12.2 \\
0.0\end{array}$ & $\begin{array}{l}(9 \cdot 2-20) \\
(8 \cdot 4-16 \cdot 8) \\
(0-16 \cdot 6) \ddagger \\
(0-17 \cdot 6) \dagger\end{array}$ & $\begin{array}{r}14 \cdot 4 \\
11.0 \\
0.0 \\
0.0\end{array}$ & $\begin{array}{r}(10 \cdot 2-16 \cdot 5) \\
(5 \cdot 2-13 \cdot 8) \\
(0-11 \cdot 5)\end{array}$ \\
\hline Adrenaline & $\begin{array}{r}10.0 \mu \mathrm{M} \\
2.0 \mu \mathrm{M} \\
1.0 \mu \mathrm{M} \\
0.5 \mu \mathrm{M}\end{array}$ & $\begin{array}{r}12 \cdot 4 \\
5 \cdot 0 \\
0 \cdot 0 \\
0 \cdot 0\end{array}$ & 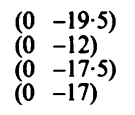 & $\begin{array}{r}14 \cdot 1 \\
7 \cdot 0 \\
0 \cdot 0 \\
0 \cdot 0\end{array}$ & 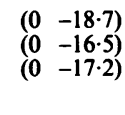 \\
\hline Collagen & $\begin{array}{l}4.0 \mu \mathrm{g} / \mathrm{ml} \\
1.6 \mu \mathrm{g} / \mathrm{ml} \\
0.8 \mu \mathrm{g} / \mathrm{ml} \\
0.4 \mu \mathrm{g} / \mathrm{ml}\end{array}$ & $\begin{array}{r}12 \cdot 6 \\
5 \cdot 7 \\
7 \cdot 5 \\
0 \cdot 0\end{array}$ & $\begin{array}{ll}(9 & -16.8) \\
(0 & -11.5) \\
(0 & -18) \\
(0 & -14.8)\end{array}$ & $\begin{array}{r}13.4 \\
4.5 \\
7.5 \\
0.0\end{array}$ & $\begin{array}{c}(11 \cdot 8-16 \cdot 5) \\
(0-10 \cdot 7) \\
(0-17 \cdot 5) \\
(0-10)\end{array}$ \\
\hline
\end{tabular}

* $p<0.05 ; \mathrm{tp}<0.02 ; \neq \mathrm{p}<0.01 ; \S \mathrm{p}<0.001$.

Aggregation is expressed as the maximum increase in optical density four minutes after the addition of the aggregating agents. Data are expressed as median values (ranges of observations in parentheses).
Table 2 Platelet responses to 5-HT, ADP, adrenaline and collagen in nine patients with primary Raynaud's phenomenon and seven with Raynaud's phenomenon associated with systemic sclerosis

\begin{tabular}{|c|c|c|c|c|c|}
\hline \multirow{2}{*}{$\frac{\text { Agonist }}{\text { 5-HT }}$} & \multirow{2}{*}{$\begin{array}{l}\text { Dose } \\
10.0 \mu \mathrm{M} \\
1.0 \mu \mathrm{M} \\
0.1 \mu \mathrm{M} \\
0.025 \mu \mathrm{M}\end{array}$} & \multicolumn{2}{|c|}{ Primary } & \multicolumn{2}{|c|}{ Secondary } \\
\hline & & $\begin{array}{r}12 \cdot 5 \\
10 \cdot 3 \\
8 \cdot 0 \\
0 \cdot 0\end{array}$ & $\begin{array}{l}(5-20) \\
(3 \cdot 8-20) \\
(0-14 \cdot 5) \\
(0-4 \cdot 8)\end{array}$ & $\begin{array}{r}11 \cdot 2 \\
14 \cdot 0 \\
7 \cdot 5 \\
1.5\end{array}$ & 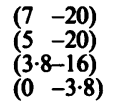 \\
\hline ADP & $\begin{array}{l}4.0 \mu \mathrm{M} \\
2.0 \mu \mathrm{M} \\
1.0 \mu \mathrm{M} \\
0.5 \mu \mathrm{M}\end{array}$ & $\begin{array}{r}15.0 \\
11.7 \\
9 \cdot 3 \\
0.0\end{array}$ & $\begin{array}{c}(11-17 \cdot 9) \\
(9 \cdot 8-15 \cdot 2) \\
(0-16 \cdot 5) \\
(0-4 \cdot 2) *\end{array}$ & $\begin{array}{r}12 \cdot 8 \\
15 \cdot 3 \\
14 \cdot 0 \\
7 \cdot 3\end{array}$ & $\begin{array}{l}(9 \cdot 2-20) \\
(8 \cdot 4-16 \cdot 8) \\
(0-16 \cdot 6) \\
(0-17.6)\end{array}$ \\
\hline Adrenaline & $\begin{array}{r}10.0 \mu \mathrm{M} \\
2.0 \mu \mathrm{M} \\
1.0 \mu \mathrm{M} \\
0.5 \mu \mathrm{M}\end{array}$ & $\begin{array}{r}12.4 \\
5.0 \\
0.0 \\
0.0\end{array}$ & 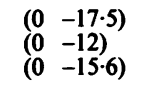 & $\begin{array}{r}12 \cdot 4 \\
5.9 \\
10 \cdot 2 \\
0.0\end{array}$ & $\begin{array}{l}(9 \cdot 5-19 \cdot 5) \\
(0-11 \cdot 8) \\
(0-17 \cdot 5) \\
(0-17)\end{array}$ \\
\hline Collagen & $\begin{array}{l}4.0 \mu \mathrm{g} / \mathrm{ml} \\
1.6 \mu \mathrm{g} / \mathrm{ml} \\
0.8 \mu \mathrm{g} / \mathrm{ml} \\
0.4 \mu \mathrm{g} / \mathrm{ml}\end{array}$ & $\begin{array}{c}12 \cdot 5 \\
\frac{8 \cdot 2}{0 \cdot 0}\end{array}$ & $\begin{array}{l}(10 \cdot 6-16 \cdot 8) \\
(0-16) \\
(0-14 \cdot 8)\end{array}$ & $\begin{array}{c}12 \cdot 7 \\
7.0 \\
0.0\end{array}$ & 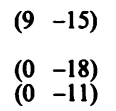 \\
\hline
\end{tabular}

$* \mathrm{p}<0.02$

Aggregation is expressed as the maximum increase in optical density four minutes after the addition of the aggregating agents. Data are expressed as median values (ranges of observations in parentheses).

Three patients (19\%), two with primary and one with secondary Raynaud's phenomenon, but no controls, showed irreversible platelet aggregation to 5-HT $(10 ; 1 ; 0 \cdot 1 \mu \mathrm{M})$. Six patients $(38 \%)$, one of nine $(11 \%)$ with primary, and five of seven $(71 \%)$ with secondary Raynaud's phenomenon, but no controls, had detectable secondary wave of aggregation to low concentration of $\operatorname{ADP}(0.5 \mu \mathrm{M})$. These patients had significantly lower threshold concentrations of both 5-HT and

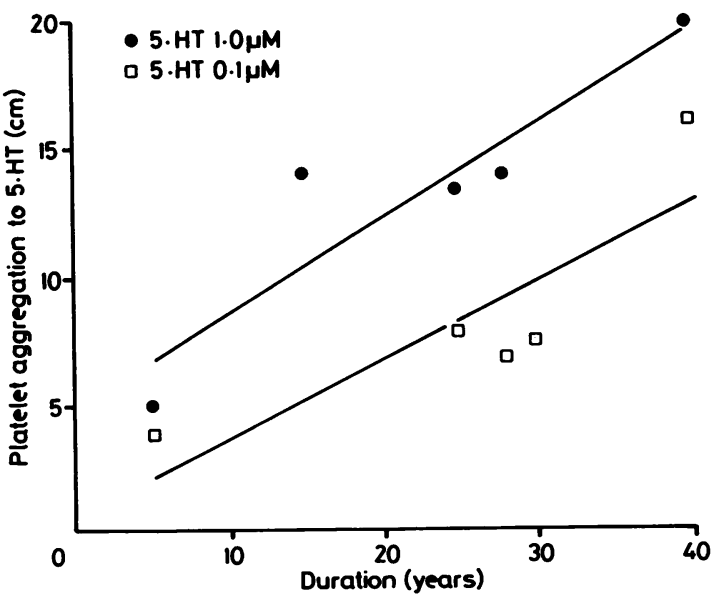

Figure Association between platelet response to 5-HT and duration of disease in six patients with Raynaud's phenomenon associated with progressive systemic sclerosis $(1.0 \mu M-r=0.919, p<0.01 ; 0.1 \mu M-r=0.844, p<0.05)$. 
ADP required to induce aggregation than patients who did not show secondary aggregation $(5-\mathrm{HT}-0.03$ (0.004) $v 0.8(0.016) \mu \mathrm{M}, \mathrm{p}<0.02 ; \mathrm{ADP}-0.4(0.004)$ $v 1.4(0.16) \mu \mathrm{M}, \mathrm{p}<0.001)$.

Aggregation variables were independent of age and sex of subjects as well as the presence of antinuclear factors and anti-centromere antibodies.

\section{Discussion}

Our data show that platelets from patients with Raynaud's phenomenon had an enhanced in vitro response to a wide range of concentrations of 5-HT and to low concentrations of ADP, but normal responses to collagen and adrenaline. Moreover, low 5-HT and ADP concentrations yielded the greatest platelet responses in more severe cases (long-standing progressive systemic sclerosis for 5-HT; progressive systemic sclerosis for ADP).

Data on aggregation in vitro of platelets from patients with Raynaud's phenomenon are scanty and controversial. ${ }^{112}$ In contrast to Friedhoff et al, who reported hyperaggregation to 5-HT in early but not in late onset progressive systemic sclerosis, ${ }^{13}$ the platelet response to 5-HT in our patients with progressive systemic sclerosis was greater in diseases of long duration. Moreover, no association was found between platelet aggregation and disease duration for our patients with primary Raynaud's phenomenon.

The reason why platelets from patients with Raynaud's phenomenon hyperaggregated in vitro to 5-HT and ADP, but not to collagen and adrenaline, is intriguing. The increased platelet sensitivity to 5-HT we found may be consistent with the enhanced response to 5-HT but not to other vasoconstricting substances observed for cutaneous vessels from patients with progressive systemic sclerosis. ${ }^{14}$ It might also be associated with altered 5-HT2 receptor density or activation. Should this be the case, the enhanced platelet response to ADP might be related to the abnormal platelet sensitivity to 5-HT released during aggregation. On the other hand, it is not possible to rule out that platelet aggregation patterns we observed are related to enhanced generic platelet reactivity.
It is concluded that platelets from patients with Raynaud's phenomenon show an enhanced in vitro response to 5-HT and ADP, a phenomenon consistent with such patients having platelets which are hypersensitive to 5-HT.

\section{References}

1 Biondi ML, Marasini B, Bianchi E, Agostoni A. Plasma free and intraplatelet serotonin in patients with Raynaud's phenomenon. Intern J Cardiol 1988;19:335-9.

2 Roald OK, Seem E. Treatment of Raynaud's phenomenon with ketanserin in patients with connective tissue disorders. $\mathrm{Br}$ Med J 1984;289:577-9.

3 Lukac J, Rovensky J, Tauchmannova H. Effects of ketanserin on Raynaud's phenomenon in progressive systemic sclerosis: a double-blind trial. Drug Ex Clin Res 1985;11:659-63.

4 Tomilson IW. Monitoring cutaneous circulation in Raynaud's phenomenon with observations on ketanserin. In: Davis E, ed. Advances in Microcirculation. Vol 12. Basel: Karger, 1985: $37-52$.

5 Seibold JR, Terregino CA. Selective antagonist of S2-serotoninergic receptors relieves but does not prevent cold-induced vasoconstriction in primary Raynaud's phenomenon. $J$ Rheumatol 1986;13:337-40.

6 Marasini B, Biondi ML, Bianchi E, Dell'Orto P, Agostoni A. Ketanserin treatment and serotonin in patients with primary and secondary Raynaud's phenomenon. Eur J Clin Pharmacol 1988;35:419-21.

7 Kallenberg CGM, Vallenga AA. Platelet activation, fibrinolytic activity and circulating immune complexes in Raynaud's phenomenon. $J$ Rheumatol 1982;9:878-84.

8 Hutton RA, Mikhailidis DP, Bernstein RM, Jeremy JY, Hughes GRV. Assessment of platelet function in patients with Raynaud's syndrome. J Clin Pathol 1984;137:182-7.

9 Reilly IAG, Roy L, Fitzgerald GA. Biosynthesis of thromboxane in patients with systematic sclerosis and Raynaud's phenomenon. Br Med J 1986;292:1037-9.

10 Allen EV, Brown GE. Raynaud's disease: a critical review of minor requisites for diagnosis. Am J Med Sci 1932;183:187-200.

11 Zahavi J, Hansiton WAP, O'Reilly MJG, Leyton J, Cotton LT, Kakkar UV. Plasma exchange and platelet function in Raynaud's phenomenon. Thromb Res 1980;19:85-93.

12 Meyerhoff J, Dorsch CA. Platelet aggregation in systemic sclerosis (PPS). Arthritis Rheum 1981;24(Suppl):S85.

13 Friedhoff LT, Seibold JR, Kim HC, Simester KS. Serotonin induced platelet aggregation in systemic sclerosis. Clin Exp Rheumatol 1984;12:119-23.

14 Winkelman RK, Goldyne ME, Linscheid RL. Hypersensitivity of scleroderma cutaneous vascular smooth muscle to 5-hydroxytryptamine. Br J Dermatol 1976;195:51-6.

Requests for reprints to: Dr M L Biondi, Clinica Medica V, Ospedale San Paolo, Via di Rudini 8, 20142 Milan, Italy. 